\title{
2 International marketing at the interface of the alluring global and the comforting local
}

\author{
Güliz Ger, Olga Kravets, and Özlem Sandıkcı
}

\section{Overview}

This chapter highlights the poles of global/local and standardization/adaptation and calls for a focus on the specific interaction between a local context and the global forces while forming a glocalization strategy. It focuses on a key question managers try to answer: what is the right marketing approach for a firm operating in international markets? The decision of if and how to tailor their marketing offerings to global/local market dynamics is fundamental in defining the marketing strategy of both transnationals and local companies in emergent markets. We describe how emergent market companies can successfully compete with transnational giants by developing brands that serve consumers bridge various sociocultural tensions in their daily lives. We focus on one such tension: the alluring global and the comforting local. Two cases - a Russian brand of cosmetics, Green Mama and a Turkish brand of cola, Cola Turka - demonstrate effective business solutions that bridge the desire for both the local and the global. These cases also underscore that the specifics of the design and implementation of glocalization as well as cultural analysis of the sociohistorical context of a national market are vital for successful marketing.

\section{Cultural positioning: overcoming the dualities of standardization/adaptation and global/local}

Firms have been grappling with the trials and tribulations of global standardization, local adaptation, and recently, glocalization. Standardization indicates operating "as if the world were one large market" (Levitt 1983: 92). The proponents of this approach note that with globalization the world becomes homogeneous; in particular, technology, media and tourism cause the convergence of consumer tastes and preferences across geographies. Thus, companies can and should capitalize on this homogeneity to attain economies of scale, scope, and rapid diffusion of products. This approach also allows a company to establish its reputation as a global player and to build/maintain a coherent brand image across the world, thus to increase its brand equity.

The opponents of standardization point to the persistent differences in cultural, political, legal, and economic environments worldwide; hence they advocate adaptation of the marketing mix to suit local market conditions and characteristics. They argue that the rationale for standardization lies primarily with supply issues and lacks sufficient consideration of demand: consumers, cultures, purchasing power, and market infrastructures. Hence, by offering a standardized marketing program, a transnational company would lack the 
proximity to local cultures and consumers, and lose on opportunities that a local market presents, or face consumer resistance and fail.

Currently, glocalization, a blend of global standardization and local adaptation, is the common recommendation for global marketers. This involves finding an optimal combinatory solution - a glocal solution - that would reflect and respond to the complex array of factors pertaining to the company, brand, consumers and local cultures. Glocalization entails local adaptation of global strategies. For example, Coca-Cola runs special advertising campaigns aligning the beverage with local holidays, such as the Chinese New Year and Muslim Ramadan (http://popsop.com/31409). McDonald's offers locally customized flavors in addition to its standard menu, such as Aussie Burger in Australia, McTurko (http://www. mcdonalds.com.tr/Urun_Detay.asp?mainId $=1 \&$ subId $=0 \&$ CatID $=1 \&$ ItemID $=10$ ) in Turkey and soy burgers in South-East Asia.

Glocalization is a major concern not only for transnational but also the local firms competing with them. With the influx of foreign companies and brands, managers of domestic firms need to decide on how to respond to the internalization of their markets. Many "smart" local companies in emerging markets such as Brazil, Mexico, China, India, Indonesia, Thailand, Turkey, and Russia not only defend their market shares against the transnationals, but also have become market leaders. For example, in Brazil the local computer manufacturer Grupo Positivo commands more market share than global giants such as Dell and HP. Mexican hypermarket chain Grupo Elektra competes head on with Wal-Mart. The biggest dairy manufacturer of Russia, Wimm-Bill-Dann Foods sells more milk than Danone. And in Turkey, the local baby shampoo brand Dalin enjoys market leadership while Johnson and Johnson and Nivea are followers.

Commonly recommended and pursued means for local companies to compete with transnationals are to capitalize on their economic, human and technological competitive assets and capabilities, position in the domestic industry, and familiarity with the local infrastructure and preferences. For example, the Philippines-based fast-food chain Jollibee pursued standardization by benchmarking transnational fast-food chains' operations to devise their own operation system. The company also implemented adaptation by developing a Philippino cuisine-based fast-food menu. By successfully glocalizing, that is, combining standardization and adaptation, Jollibee expanded its business beyond the Philippines to South-East Asia and even the US.

Overall, standardization, adaptation and glocalization can each be effective strategies under specific market conditions. In essence, these strategic options relate to the debates on globalization: the socio-cultural homogenization and heterogenization or convergence and divergence. Just as technology, media and tourism create and promote a transnational culture of sameness, they also highlight and reify differences among nations, regions, and ethnic groups and the peculiarities in local cultures, traditions, and lifestyles. Many managers take international marketing to be about deciding on a degree and balance of localness and globalness in their activities. Then, the decision becomes whether and to what extent to employ a particular strategy. To that end, companies are conventionally advised to consider cultural differences and similarities. When similarities are prevalent, standardization and when differences are prevalent, adaptation seem to be preferred. However, rather than being opposites, homogenization and heterogenization co-exist, react to, and shape each other. Globalization is about the coexistence and interpenetration of the global and the local (Appadurai 1990). That interpenetration unfolds in a specific manner in different times and spaces. 
The cultural perspective considers the coexistence and interpenetration of the global and the local, and hence it goes beyond viewing culture as a set of differences and similarities. As such, it attends to cultural resources, forces and tensions and negotiations thereof. Adopting a cultural perspective enriches the arsenal of managers by making apparent the not-so-easily seen opportunities. Cemex México's Patrimonio Hoy program illustrates this business logic. As part of the program, Cemex, a building material producer, sets up clubs to organize self-financing of home building and improvement projects for low-income families (Leteller et al. 2003). These clubs are modeled after the long-existing tanda groups, where each member contributes money weekly and a different member receives the yield of the week in cash. In Cemex's clubs, members receive building materials instead of cash. Thus, Cemex uses the tanda group practice as a cultural resource to create a market for its products among low-income consumers. Cemex's marketing draws on a situated understanding of cultural values. It addresses the tension between the local value of a community spirit and the global desire for improved living conditions for an individual family. Mexicans want a social identity as respected members of their community by, for example, contributing financially to communal celebrations. They also want to be individuals who provide well for their own households. These opposing cultural forces create a tension for low-income consumers. Cemex helps them negotiate and resolve that tension. The company enables community affiliations by, for example, sponsoring communal celebrations of family achievements in building their house and the meetings of Patrimonio Hoy clubs. It also enables an individual family to own a house by organizing affordable financing and providing technical advice, delivery, and warehousing services. Thus, Cemex created a unique customer value by identifying and mobilizing cultural resources, forces and tensions. Cemex leveraged its cultural capital $^{1}$ in a product category where foreign companies lacked such capital and was able to differentiate cement - a prototypical commodity and become the world's number three cement producer. The success of Cemex provides one example of the merit of the mobilization of cultural resources in generating customer value (Ger 1999).

Attending to cultural resources, forces and tensions often requires a reflexive distance to the local culture, that is, taking an outsider's as well as an insider's perspective to question taken-for-granted understandings. A reflexive distance can be attained by being a foreigner or having been acculturated to a different culture. Consider the reinvention of traditional root dyes in Turkey after their disappearance in early twentieth century from the scene of traditional carpets. They were rediscovered in the 1970s by individuals who were either foreigners or Turks educated abroad. Another example is Inca Cola in Peru, invented by an immigrant British family based on an ancestral concoction. It has been so successful that it commands a 31 percent share of the soft drink market, followed by Coca-Cola's 26 percent. Perhaps it is difficult for local entrepreneurs to notice the taken-for-granted value of a cultural resource that outsiders can see more readily. Thus, reflexive distance is of great use in the ability to detect and imagine the potential market value in a particular cultural resource, a potential to be capitalized on by cultural entrepreneurship.

Understanding of cultural resources, forces and tensions also requires managers to get even closer to consumers than possible by conducting cross-cultural surveys. While these surveys magnify and over-generalize differences and similarities, they overlook cultural tensions and negotiations. However, in their daily lives consumers encounter the coexistence and interpenetration of the local and the global, and often have to deal with the related tensions and contradictions. Marketing solutions that help negotiate such tensions are likely to succeed. Among these tensions, we now focus on a specific one experienced by consumers who encounter the global within a particular local. 


\section{The allure of the global and the comfort of the local}

Consumers relate to global products in diverse ways. They can embrace global(ized) goods for the sake of modernity or status, or reject them in pursuit of nostalgia and authenticity, or connect global products to local consumption practices and give them local meanings (Ger and Belk 1996). Underlying such consumer strategies in emergent markets is the co-presence of two seemingly opposing desires - the desire for the seductive foreign and the desire for the authentic and familiar local (Wilk 1999). On the one hand, consumers enjoy an intimate connection to local goods. The familiarity with local products provides a sense of comfort and security; their history assures a sense of continuity and tradition (Ger 2005), perhaps poignantly illustrated by enduring preference for Russian-made vodka in Russia. On the other hand, consumers are attracted to the foreign - as they drink Starbucks coffee or walk the streets with iPods, they feel they are a part of a global community and modernity. Even if they cannot afford iPods, poorer consumers feel closer to the rest of the world when enjoying the little luxury of drinking Coke or eating a Mars bar.

The "allure of the foreign" (Orlove 1997) is prominent globally. There is widespread enthusiasm for Western/Northern goods across all classes in Latin America, Africa, and Asia. Compared to consumers in developed countries, consumers in developing countries have more favorable attitudes toward foreign products. European or North American goods signify quality and mark status, modernity, and global commonality. In addition, the preference for the foreign over local equivalents is driven by the desire to know more about the world, to become more sophisticated, and to create a "local identity on a global stage" (Wilk 1999: 253).

This consumer preference for the foreign in developing countries is also reflected in the adoption of foreign or foreign-sounding names for domestic products. For example, two major Turkish snack producers, Ülker and Eti, often use foreign languages (Finger, Petit Beurre, Rio Black) and foreign-sounding/-looking names (Haylayf - "high life" in Turkish phonetics; Alpella - reminiscent of the Alp mountains) in branding. Similarly, middle-class neighborhoods in Turkey and Russia frequently feature stores with foreignified names.

However, such glocalization, in the form of international associations, can turn against a firm due to some political or cultural incidents. For example, the allusion to Italian style and association to Italian culture exercised by Bellona, a furniture manufacturer and retailer in Turkey, backfired when a political crisis broke out between Turkey and Italy in 1998. At the time, the leader of Kurdish terrorists was in hiding in Italy. Hostile reaction against Italy arose in Turkey and many Turkish consumers boycotted Italian brands, to which Italian firms in Turkey tried to respond through various declarations. Although it was not an Italian firm, Bellona also ran an advertising campaign during the period stating that 100 percent of its capital was Turkish and that its products were not made in Italy. Thus, while the allure of the foreign is strong, it necessarily plays out in the delicate scene of international politics and, hence, may backfire, even if temporarily. In addition to cultural forces and tensions, broader political, economic, and social events also set the frame and impact the success of glocalization. Socio-historical conditions, either long-standing or recent, shape the meanings attributed to "foreign" and Western versus domestic brands and motivate choices in a specific market. A set of particular historical political and economic relations between one developing country and the "West" plays a crucial role in shaping the opposing desires for the local and the global in that country. So, standardization, adaptation, or glocalization decisions pertain to and thus should consider not only a desired cultural fit based on differences and similarities but also the specific international interactions. 
Regardless of and in addition to particular short-lived or long-standing international interactions, there is the "eternal struggle" between and the "dance" of "seductive globalism" and "authentic localism" (Wilk 1999). The tension between seductive globalism and authentic localism relates to issues of social identity. Individual consumers use the global consumer culture together with the local culture to navigate and position themselves in local identity hierarchies. Rather than merely clash, the seemingly opposing desires talk to each other, interact, and transform each other. The companies that find a way to ease the tension between the two desires by mingling the global and the local win. Implementation of glocalization will be effective to the extent that a particular design of the marketing mix and positioning help different consumer segments carry out their own identity projects.

The cultural perspective offers various advantages over conventional approaches to international marketing. By focusing on cultural resources, forces, and tensions, it reveals innovative marketing solutions, from new product development to creating new markets, financing systems and distribution networks. This is in contrast to the conventional approaches which emphasize cultural similarities and differences and concentrate on adjusting an existing marketing mix to a particular market depending on the extent of the cultural fit between home and host markets. Furthermore, analysis of culture based on similarities and differences assumes a static national culture and static life-style segments, such as traditional and modern lifestyle segments or ethnocentric and cosmopolitan consumers. However, analysis of culture based on the cultural resources, forces, and tensions brings to the fore the coexistence and the interpenetration of the global and the local and the dynamism thereof. Attention to such dynamism enables managers to create new markets and receptive segments, rather than merely cater to existing markets and segments.

Adapting such a cultural perspective requires a new mindset and methods of market research and consumer intelligence. The conventional recommendation to international firms is that, in order to make adjustments in their marketing mixes according to "cultural differences," they should measure the degree of difference found across countries on a standard set of cultural values such as individualism-collectivism or masculinity-femininity. In this approach, culture is treated as a factor that influences marketing decisions. As such, this approach reduces culture to a static set of stand-alone characteristics that are supposed to represent the whole country. Moreover, seeking to measure and compare cultures according to a limited set of values is too reductive to discover uses and meanings of consumption. The focus on preferred end-states ignores the very essence of consumption: how consumers reach these end-states in particular contexts. Consumers act differently in different situations and their actions are by no means always consistent (Holt 1994). Conventional comparative approaches to studying "cross-cultural behavior" have become increasingly inadequate to capture the complexity of cultural dynamics in the global world (Askegaard et al. 2009; Nakata 2009). Instead, the globally interconnected political, economic and cultural forces that constitute local and global markets call for innovative forms of ethnographic research and multi-sited ethnographies.

In sum, the cultural perspective highlights that managers of transnational and domestic companies should not view global and local as opposites and strive merely for more or less localness and globalness. International marketing in general and glocalization in particular should be about enabling consumers to resolve their daily tensions with a specific global/local composition of a market offering. Companies which find ways to reflect various possible resolutions of the alluring globalism-authentic localism tension through their positioning and differentiation strategies are likely to win the hearts and minds of consumers. 
The following cases illustrate how a Russian cosmetics and a Turkish beverage company have benefited from the cultural perspective. They both tapped into complex global-local tensions in different localities and have generated business successes.

\section{Mingling the foreign and the familiar: two cases}

\section{Green Mama cosmetics: with a scent of home}

In the early 1990s Russia, all things "foreign" were invariably heralded as stylish and prestigious and of superior quality and value. After years of product shortages, long queues and what many Russians considered poor quality products, foreign goods, previously forbidden to the general public and accessible only to a few, were embraced as tangible signs of the country's Westernization and democratization. However, the mid-1990s witnessed a shift in consumer preferences toward local products. Some interpreted this as an expression of Russian nationalism. In "The Taste of Nationalism," Caldwell (2002) suggests that Moscovites prefer local products because of the concern with national integrity, arising from market-oriented reforms and the influx of foreign goods. Through their choice of local products, consumers in Russia strove to (re)assert their national cultural identity, sense of belonging, and the uniqueness of Russia in an increasingly transnational world.

Although compelling, this reasoning does not account for the differences in preferences among different categories of goods and among different social groups (Patico 2003). The "apparent ethnocentrism" of Russian consumers is best understood when considered along the following lines of tensions. The first tension centers on consumers' concerns with quality and their experiences of the post-Soviet free market. In the 1990s transition from a socialist to a market economy, counterfeiting was rampant; an army of one-night entrepreneurs manufactured goods in garages and decorated them with foreign labels. There were many small-scale producers seeking to capitalize their home-grown know-how within the newly liberalized production system. The flood of forged and genuine imports and new local goods created a sense of a chaotic market - a space out of control where producers rule and anything goes as long as it is profitable, where consumers should take care not to be duped or poisoned. In that context, consumers chose domestic (often former Soviet) goods because they offered shoppers a sense of familiarity, safety and security. In Soviet times, the state guaranteed and enforced product safety through a system of quality standards. The system implied that all goods were produced to "scientific standards" developed in research institutes independent of an individual producer's capabilities and external to its interests. In contrast, the workings of the free market with its self-regulation ethos was less understood, and, given their initial market experiences, people were skeptical of a market's quality control system. Thus, consumers often opted for the familiar guarantees of the state, choosing seemingly state-endorsed products (e.g., Kenneth 2003a).

The second tension centers on the country's perceived position within a global hierarchy of economic development. For many in Russia, Gorbochev's perestroika (reconstruction) was a promise of "finally catching up with the rest of the (Western) world" and becoming a European country, particularly in terms of lifestyle and consumption. However, due the economic instability in the 1990s, specifically the 1998 currency devaluation, Western goods became too expensive, hence out of reach for many. That exposed as a fantasy the imagery of the West as a place of abundance and comfort for all which many Soviet people believed. Also, in Soviet times, Western goods were believed to be superior in every way - better quality and healthier, more aesthetic and technologically advanced, and above all, they were 
seen as magical, capable of making a person happy. Thus, disillusionment was inevitable. However, that disillusionment was not attributed to unrealistic initial expectations, but to the "fact" that Western firms were not selling their best products in Russia. There was a pervasive belief that firms designated some cheap, low quality, even harmful goods for "export to Russia," because Russia was becoming a poor "Third World" country (Patico 2003). The belief was corroborated by the observations that Russian factories were closing, the economy was being sustained on raw materials exports and the public believed "nobody wants our goods." In short, underlying the tension was the concern that the changes were transforming Russia into a "Third World" country, thus driving people further away from the desired "Western way" of living.

The third tension is the perestroika-induced disjuncture between economic and cultural capital experienced by some social groups in Russia. The study of teachers in St Petersburg (ibid.) found that reforms led to the economic impoverishment of these formally "respectable representatives of mass intelligentsia" - a social class of well-educated people engaged in intellectual labor directed at the development and dissemination of culture. As their incomes shrank in absolute and relative terms, teachers found themselves marginalized, unable to enjoy the long-desired Western goods or partake in shaping the newly emergent market culture. Thus, many adopted a cynical and critical stance towards the market economy; notably, teachers often drew on the global discourses of ethical consumption to advance their criticism and explain their (local-oriented) consumption patterns.

How is it possible for a firm to tap into these complex global-local tensions in Russia and become a success? Let's look at one example. Green Mama is among Russia's top five manufacturers and marketers of cosmetics. Recently nominated "the best Russian brand" (Green Mama n.d.), it competes in the \$4 billion Russian cosmetics market alongside the former Soviet giants (e.g., Kalina and Novaya Zarya) and transnational corporations (e.g., Proctor \& Gamble and L'Oréal). The company is "a family-owned corporate entity" that was established in 1996 by Oleg and Irina Nasobin (Green Mama n.d.). From the beginning, the company promoted itself as international with operations in the Czech Republic, France and Russia and specialist employees from Russia, France, Japan, Ukraine, and South Africa. Later, the company set up headquarters in Grass (France) and production facilities in Russia, and presented itself as "Russian company with a French address" (The New York Times, 2000). The French connection was crucial for the company's initial success, because former Soviet consumers believed that the best quality cosmetics came from France, and more generally, the allure of the foreign was still strong (ibid.) Equally important for the company was to assert its Russian "roots." It did so in a powerful way - the company's positioning was based on the use of native Russian plants as active ingredients. In his interviews, Mr. Nasobin noted that the ribwort, a Russian roadside weed or a daisy are "our own, close to a Russian heart," hence more suitable for a Russian than foreign jojoba. In a sea of foreign-made products with attractive packaging but strange ingredients, Green Mama offered consumers what they were looking for - familiar ingredients that had the smell of childhood and/or Russian nature, in a foreign package. Similarly, the company's name - Green Mama - maintains a local-foreign duality: although written in English it is understandable to anyone with minimal knowledge of English and the word "mama" is Russian for "mother," implying home and care. Thus, as the New York Times (2000) writes, the company's winning formula was "homegrown extracts with a made-in-France label."

In a market plagued by distrust, as a small company with an unknown name, Green Mama had to establish a reputation as a quality producer. It addressed the challenge in several 
ways. First, it linked itself to the geographical area, known as "the global capital of cosmetics and perfumery and the center for global research into essential oils and a venue for top scientific conferences" (Kenneth 2003b: 2). Second, it set its research laboratories in France away from the mass production facilities in Russia, thereby creating the perception of external quality standards, i.e. to a degree, replicating the Soviet model (described above). Significantly, to reassure concerned consumers, the company explained that its standards differ from those of transnational corporations. For instance, the color of a cream may vary from tube to tube because, unlike many transnationals, the company produced only natural cosmetics; it used all natural ingredients, characteristics of which can change depending on the season. Third, the company emphasized that it conducted research and manufacturing for some well-known foreign brands, and exported its own "Russian-made products" to 34 countries (Green Mama n.d.).

Green Mama defines its target audience as the "representatives of intelligentsia," educated people with "high cultural level," and someone "who pays attention to his or her health and body, and is not susceptible to direct effects of aggressive advertising ... someone who knows exactly what s/he wants, or someone who thinks before buying anything" (ibid.). Throughout the years, the company has been successful in aligning its marketing strategy with the sensibilities of this consumer group. Green Mama does not advertise nationally, instead it uses local newspapers, radio, television and a multi-language web-page. Indeed, Mr. Nasobin insists that he does not believe in marketing, market competition, and operational figures since the company has "a different orientation on the market." He states:

Unlike typical US companies our aim is not to control everything in the sector by absorbing or swallowing others.... We are in the business of cosmetics production. Therefore, our central aim is to produce quality products, try to sell them, and whatever we get is all ours. We also don't have a goal of making all women use our products, etc.

(Kenneth 2003b: 22)

Such rhetoric echoes the sentiments of the "representatives of intelligentsia," who have been hit the hardest economically and socio-culturally by the reforms and are critical of "the Western market" with its predatory competition and in-your-face marketing tactics.

Consistent with the ethos of this target audience, the Green Mama's "quality products" are natural, ethical and eco-friendly. The company followed an intricate path to assert this "natural" image. It distanced itself from transnational, industrialized producers, while communicating that Green Mama was not a home-based operation with grandmother's pots either (Green Mama n.d.). Green Mama claims to use cutting-edge technologies, engage in scientific research and employe top experts, to create superior quality recipes and produce on a modest scale. The company's publicity materials educate consumers about production processes and characteristics of active ingredients used. Furthermore, Green Mama's advertising and packaging are dominated by a soft-green pallet and draw on associations with the local nature and sensory experiences of native plants. Yet, Green Mama is grounded in the global concern with ethical production. For Green Mama, "ethical" includes a sustainable use of natural ingredients accompanied with a lack of animal testing, no animalderived products, no preservatives, not using genetically modified ingredients, or chemical enhancers of color and scent. Moreover, "ethical" means honesty (hence, the detailed product labeling) and a fair price for consumers, whose "ethical concerns is a part of the company's ethical image" (ibid.). 
Green Mama's mission is similar to that of many other international companies - a developer of "eco-friendly \& chic cosmetic products for the idealists of the world, for all those who read the label before choosing a cream" (ibid.). However, the company achieved its success by responding to the global-local tensions as they play out in the post-socialist Russia. Green Mama used the foreign side to distance itself from the ills of the reform era market in Russia, while endorsing the quality of its products. It used the local side to differentiate itself from foreign competitors, which have been dominating the hearts of consumers in Russia since Soviet times, and to appeal to the sensibilities of those locals, who have been disenfranchised by the market. Overall, Green Mama managed to bridge the foreign-local tension by linking the local anxieties with global concerns.

You can find out more information and take a look at some of Green Mama's products on their website: http://www.greenmama.ru.

\section{Marketing Cola Turka in Turkey}

Until recently, the cola market in Turkey, similar to many other countries, was dominated by two giants, Coca-Cola and Pepsi Cola. Coca-Cola was the market leader with more than 60 percent share, and Pepsi Cola commanded around 25 percent share (Thompson 2005). In July 2003, a local brand, Cola Turka, entered the market with significant advertising support and ambition to become a key player. Cola Turka is manufactured and marketed by Ülker, a giant Turkish company that operates in fields as diverse as food and beverage, information technologies, logistics, packaging, and real estate. Ülker was established in 1944 as a small manufacturer of cookies; over the years it developed into a global firm that now exports its products to over 110 countries (www.ülker.com.tr/en). In 2007, the group purchased Godiva Chocolatier. Although Ülker has never projected an Islamic image in its marketing communications, the company is well known for its ties to Islamist politics in Turkey. The group's entry to the cola market signaled a direct attack on Coca-Cola.

All over the world there are several local brands that position themselves as "anti-CocaCola" and resist Coca-Cola as a symbol of American colonization and cultural imperialism. Brands such as Mecca Cola, Zam Zam Cola and Qibla Cola target Muslim consumers and attempt to position themselves as morally superior alternatives to Coca-Cola. For example, Mecca Cola communicates with its audience through the tag lines "No more drinking stupid - drink with commitment" and "Don't shake me, shake your conscience!" The company publicizes that it donates 10 percent of its profits to charities in the Palestinian territories. Like Mecca Cola, Qibla Cola aims to offer "real alternatives to global consumer brands that support unjust policies" (Qibla Cola). In addition to Qibla Cola, the company sells Qibla Fantasy (orange and mango) and Qibla 5 (lemon and lime, named after the five pillars of Islam). There are other Muslim colas dedicated to taking market shares from Coca-Cola. However, they face distribution problems and typically remain as "niche" products. With their low market shares, they pose little threat to Coca-Cola.

Unlike other Muslim colas, Cola Turka did not position itself as "anti-cola" and emphasize its religious connotations. On the contrary, Cola Turka claimed to be the cola that not only Turks but also Americans would prefer to drink. The launch commercials aimed to convey the idea of "Drink Cola Turka, become Turkish." The commercials were produced by the Istanbul affiliate of Young and Rubicam and featured American actors Chevy Chase and Bob Brown. In the first commercial, Chase walks through Times Square as a car full of Turkish men, wrapped in their national flag, drive by celebrating a soccer victory. Perplexed by what he saw, Chase enters a diner only to realize that a New Yorker (Bob Brown) in a 
cowboy hat, sitting at the counter, speaks to him in Turkish after drinking Cola Turka. In the second commercial, Chase returns to his suburban home to discover his wife preparing a traditional Turkish meal for the children and their grandparents. At dinner, everyone drinks Cola Turka and begins singing the Turkish anthem of the youth, a popular song associated with Turkish national independence. Chase can't resist any more and sips Cola Turka. In the last scene Chase wears a bushy black mustache, a stereotypical symbol of Turkishness and finally becomes "Turkishized." The slogan "Cola is the usual coke, Turka is our Turka" appears at the end.

The commercials were an immediate success. Brand name awareness increased rapidly and, by October 2003, Cola Turka had captured 20 percent of the market share (Thompson 2005). However, in the coming months, the share dropped to around 10 points. There were several reasons for the drop. Coca-Cola responded swiftly and aggressively and engaged in a price war. Some consumers who initially tried the product claimed that they did not like its taste. And some others, who learned that Cola Turka was produced by Ülker, a company associated with Islamist politics, did not want to purchase the brand (Sandikc1 and Ekici 2009). Nonetheless, Cola Turka was able to capture a loyal and substantial group of consumers who believed that Cola Turka offered a strong, tasteful, and ideologically correct alternative to Coca-Cola. According to company officials, Cola Turka now commands a 13 percent market share and competes head on with Pepsi Cola for the number two position in the market. Ülker exports Cola Turka to more than 15 countries, including the USA and France, and has extended the product line by offering new varieties such as Cola Turka Sifir (Zero).

What are the reasons underlying Cola Turka's success? In order to understand how Cola Turka became a key contender in the cola market, one needs to examine the socio-cultural underpinnings of the brand's marketing strategy. Similar to Inca Cola, Cola Turka stayed away from an explicit "anti-cola" positioning. Instead, it mobilized both nationalist pride and cosmopolitan subjectivity and sought to appeal to consumers by projecting a model of "global Turkishness." It claimed to be as good as the foreign and yet national at the same time. However, Cola Turka did not simply exploit Turkish consumers' nationalist feelings. Rather, it articulated the neoliberal nationalist discourse and offered its consumers a way to reconcile the tension between the local and global.

Until the 1980s, Turkey's economic development strategy was based on the importsubstitution model. The semi-controlled mixed economy consisted of a domestically oriented publicly and privately owned industrial sector and mostly privately owned small agricultural businesses. With many restrictions on foreign direct investment and high import tariffs, local companies were protected from global competition. The range of consumer goods was limited and their quality was mediocre and the country frequently suffered from product shortages. In the $1980 \mathrm{~s}$, the economy went through a neo-liberal restructuring. With the opening up of the country to global competition, Turkish consumers found themselves bombarded with foreign brand name products that they either had not heard of before or could only have purchased on the black market. Given the relative developmental status of the country and the prices and standing of its products in both domestic and world markets, respect and esteem for national identity and national products had been low. Similarly, pride in local culture and local products had dissipated and respect in what the locals could do had diminished. In such a context, except for elite cosmopolitans, most consumers' reactions to foreign products were mixed. On the one hand, foreign brands were regarded as prestigious and of high quality and hence much more desirable than the local ones; but on the other hand, foreign brands lacked the familiarity and the casual comfort of local products. 
In the late 1990s, there was a greater variety of products, both local and imported, along with a greater quality range for both. Along with such proliferation, there has been a reinterpretation of the local and the traditional. Products that offered a sense of Turkishness but with a global sensitivity began to achieve significant success. For example, a show entitled Sultans of the Dance (the title is indeed in English) has become hugely successful. It is a Turkish version of the Irish Riverdance show and consists of stylized folk dances and music from various regions of Turkey with allusions to ancient Anatolian myths. Many proud viewers comment that "it is great to see that we can accomplish such a professional, world class show." Products that successfully blend Turkishness with globalness, such as Ottoman-inspired luxury hotels and spas or Starbucks-like Turkish coffee chains, have begun to enjoy increasing shares and profits. That has been the case even for electronics which started to sell globally and advertise their global sales successes, depicting Western consumers using Turkish electronics. They convinced many consumers that Turkish brands are now as good as the global ones, and that "we can produce electronics as well as anyone else." Similarly, Cola Turka skillfully responded and took advantage of the tension between Turkishness and globalness. From the very beginning, it has strategically and successfully articulated a sense of global Turkishness. However, while Cola Turka emphasized its local roots in its marketing communications activities, it sought to distance itself from projecting a hardcore nationalistic image. By emphasizing self-respect at the national level and seeking recognition at the global level, Cola Turka has won the hearts and minds of many consumers.

The website for Cola Turka can be found at: http://www.colaturka.com.tr

\section{Managerial implications}

Green Mama (Russia) and Ülker's Cola Turka (Turkey) devised unique marketing strategies in their respective internationalized markets in order to compete in industries dominated by transnational giants. Both companies managed to successfully compete by attending to complex global-local tensions and taking advantage of their cultural capital. Green Mama and Ülker's Cola Turka serve as models for transnational giants as well as other emergent market companies. Their marketing solutions respond to complex global dynamics within a specific market and pertain to the company's capabilities, industry's structure and competition. Also, the solutions are built on nuanced understandings of historical cultural sensibilities and socio-political contexts that shape consumer preferences. Thus, the solutions are sensitive to the existing cultural forces and tensions and incorporate them to ease the associated consumer anxieties. Accordingly, as with Cemex México (discussed above), the key issue of successful glocalization is the specification of how it is to be implemented rather than solely about deciding on the extent and balance of localness and globalness in marketing activities. These cases illustrate: (1) the usefulness of the mobilization of cultural resources in generating customer value and thus competing with transnational giants; and (2) the merits of attending to the coexistence and interpenetration of the global and the local forces.

In today's interconnected world, business success lies in dialogue within the global-local encounters. The local companies are best positioned to succeed by engaging with the global as they experience it in their markets, rather than merely imitating transnationals or being anti-global. The transnational companies are likely to win by understanding and responding to the global/local cultural forces and tensions, rather than imposing a global uniformity. 
To do this, managers need to go beyond considering only the differences and similarities between foreign and local cultures. They need to understand the tensions and negotiations among significant cultural forces that might appear to be poles. Transnationals and emergent market companies that attend to the interactions among apparently opposing cultural forces gain knowledge of various tensions local consumers face and deal with in their daily lives. To uncover such tensions, marketing managers should develop a reflexive distance to both local and global cultures. In other words, they must look at the local through the lens of the global and at the global through the lens of the local. Such knowledge allows companies to craft innovative marketing solutions that help consumers negotiate and solve cultural tensions. The emphasis on tensions suggests that consumers do not live on the poles of global or local, ethnocentric or cosmopolitan, or traditional or modern, but rather they navigate these dimensions. Thus, as the Green Mama and Cola Turka examples show, some consumers want to have both "the alluring global" and "the comforting local" and prefer marketing solutions that promise both. Companies catering to this desire for both the local and the global stand to win the hearts and minds of consumers.

\section{Review and discussion questions}

1 Compare and contrast standardization, adaptation and glocalization approaches.

2 Discuss the major strengths and weaknesses of the cultural perspective over conventional approaches to international marketing.

3 Explain what "the allure of the global" is.

4 Explain what "the comfort of the local" is.

5 What is the notion of "cultural tension" in marketing management from a cultural perspective?

6 Examine marketing practices of a transnational company such as McDonald's and discuss whether and to what extent the company attends to the cultural tensions in your country. Explain the tensions consumers face. Discuss the specific strategies that the company has or should devise to help consumers solve these tensions.

7 Find examples of companies that base their international marketing strategies primarily on standardization, adaptation or glocalization. Discuss the strengths and weaknesses of each approach.

8 Identify a cultural tension experienced by a particular consumer segment in your country (for example, the disjuncture between economic and cultural capital experienced by the intelligentsia in Russia) and discuss the implications for a transnational firm that plans to market its products to this consumer segment.

\section{Keywords}

adaptation, allure of the global, comfort of the local, consumer ethnocentricity, cultural resource, cultural tension, global marketing strategy, glocalization, historical specificity, nationalism, local marketing strategy, religion, standardization

\section{Note}

1 Bourdieu's (1986) concept referring to knowledge, cultural competencies and orientations, and social connections. 


\section{References}

Appadurai, Arjun (1990) "Disjuncture and Difference in the Global Economy," in M. Featherstone (ed.) Global Culture: Nationalism, Globalization and Modernity, London: Sage, pp. 295-310.

Askegaard, Søren, Kjeldgaard, Dannie, and Arnould, Eric J. (2009) "Reflexive Culture's Consequences," in Cheryl Nakata (ed.), Beyond Hofstede: Culture Frameworks for Global Marketing and Management, London: Palgrave Macmillan, pp. 101-24.

Bourdieu, Pierre (1986) "Forms of Capital," in J. G. Richardson (ed.), Handbook of Theory and Research for the Sociology of Education, New York: Greenwood Press, pp. 241-58.

Caldwell, Melissa (2002) "The Taste of Nationalism: Food Politics in Postsocialist Moscow," Ethos, 67(3): 295-319.

Ger, Güliz (1999) "Localizing in the Village: Local Firms Competing in Global Markets", California Management Review, 41(4): 64-83.

— (2005) "Warming: Making the New Familiar and Moral," Ethnologia Europea: Journal of European Ethnology, 35(1-2): 19-22.

Ger, Güliz and Belk, Russell (1996) "I'd like to Buy the World a Coke: Consumptionscapes of the 'Less Affluent World'," Journal of Consumer Policy, 19(3): 271-304.

Green Mama (n.d.) www.greenmama.ru

Holt, Douglas B. (1994) "Consumers' Cultural Differences as Local Systems of Tastes: A Critique of the Personality/Values Approach and an Alternative Framework," Asia Pacific Advances in Consumer Research, 1: 178-84.

Kenneth, Christopher (2003a) "Russia's World of Cosmetics and Fragrance," The Russia Journal, 524 (May 15).

(2003b) "Heading a Family Empire," The Russia Journal, 528 (July 1).

Leteller, M. F., Flores, F. and Spinosa, C. (2003) "Developing Productive Customers in Emerging Markets," California Management Review, 54(4): 77-103.

Levitt, Theodore (1983) "The Globalization of Markets," Harvard Business Review, 83(3): 92-102.

Nakata, Cheryl (ed.) (2009) Beyond Hofstede: Culture Frameworks for Global Marketing and Management, London: Palgrave Macmillan.

New York Times (2000) "International Business: Russians Want Beauty with Scent of Home," July 29.

Orlove, Benjamin (ed.) (1997) The Allure of the Foreign, Ann Arbor, MI: University of Michigan Press.

Patico, Jennifer (2003) "Consuming the West but Becoming Third World: Food Imports and the Experience of Russianness," Anthropology of East Europe Review, 21(1): 31-6.

Sandıkcı, Özlem and Ekici, Ahmet (2009) "Politically Motivated Brand Rejection," Journal of Business Research, 62(2): 208-17.

Thompson, Donald (2005) Marketing Management in Turkey: Cases and Challenges, Ankara: Gazi Kitabevi.

Wilk, Richard R. (1999) “"Real Belizean Food': Building Local Identity in the Transnational Caribbean," American Anthropologist, 101(2): 244-55. 